\title{
Stakeholders como Agentes de Mudança Institucional em Ambientes de Regulação Estatal
}

\author{
Stakeholders as Agents of Institutional Change in Environments of State Regulation
}

Stakeholders como Agentes de Cambio Institucional en Ambientes de Regulación Estatal

\author{
Davi de Paula Cabral ${ }^{1}$ \\ Diego Mota Vieira ${ }^{2}$
}

\begin{abstract}
Resumo
Organizações públicas e privadas estão sujeitas à regulação do Estado através das entidades reguladoras, mas dificilmente as instituições atenderão a todos os interesses. Neste trabalho, o objetivo é caracterizar o comportamento das organizações que buscam provocar mudança institucional para alcançar um status mais favorável. Logo, a abordagem está baseada na teoria de stakeholders conjugada com a teoria de mudança institucional gradual e transformativa. Propõe-se que as organizações reguladas atuam como stakeholders das entidades reguladoras, exercendo influência como agentes de mudança institucional. Não obstante, observa-se que os stakeholders de uma entidade reguladora atuam associados, ampliando sua relevância e capacidade de confrontar as instituições segundo seus interesses. Esse tipo de atuação proporciona vantagens, como a constituição de arenas, em que interesses e expectativas são alinhados, assim como a autorregulação com base na interpretação conveniente das instituições. Além disso, a entidade reguladora também se beneficia ao lidar com um menor número de agentes e interesses. Por fim, quanto maiores os atributos de relevância do stakeholder, maiores suas chances de propor mudanças institucionais, reduzindo as possibilidades de veto e aumentando a discricionariedade na interpretação das regras.
\end{abstract}

Palavras-chave: Teoria de Stakeholders. Mudança Institucional Gradual e Transformativa. Agências Reguladoras. Instituições.

\begin{abstract}
Public and private organizations are subject to state regulation through regulatory bodies, but institutions are unlikely to serve all interests. In this work, the objective is to characterize the behavior of organizations that seek to bring about institutional change to achieve a more favorable status. Therefore, the approach is based on the theory of stakeholders combined with the theory of gradual and transformative institutional change. It is proposed that regulated organizations act as stakeholders of regulatory entities, exercising influence as agents of institutional change. Nevertheless, it is observed that the stakeholders of a regulatory entity act in the association, expanding their relevance and capacity to confront institutions according to their interests. This type of performance provides advantages, such as the establishment of arenas, in which interests and expectations are aligned, as well as self-regulation based on the convenient interpretation of the institutions. Besides, the regulatory body also benefits from dealing with fewer agents and interests. Finally, the greater the stakeholder relevance attributes, the greater its chances of proposing institutional changes, reducing the possibilities of veto, and increasing the discretion in the interpretation of the rules.
\end{abstract}

Keywords: Stakeholder Theory. Gradual and Transformative Institutional Change. Regulatory Bodies. Institutions.

1 iD Analista no Banco Central do Brasil. Mestre em Administração pela Universidade de Brasília (UnB). Project Management Professional certificado pelo PMI. Especialista em Gestão Pública e Políticas Públicas pela Universidade de Brasília (UnB).

2 (iD) Professor do Programa de Pós-Graduação em Administração da Universidade de Brasília (UnB). Doutor em Administração pela Universidade de Brasília (UnB). 


\section{Resumen}

Organizaciones públicas y privadas están sujetas a la regulación del Estado a través de las entidades reguladoras, pero difícilmente las instituciones atenderán a todos los intereses. El objetivo de este trabajo es caracterizar el comportamiento de las organizaciones que buscan provocar cambio institucional para lograr un status más favorable. Luego, el enfoque está basado en la teoría de stakeholders conjugada con la teoría de cambio institucional gradual y transformativo. Sin embargo, se observa que los stakeholders de una entidad reguladora actúan asociados, ampliando su importancia y capacidad de enfrentar las instituciones según sus intereses. Este tipo de actuación ofrece ventajas, como la constitución de arenas, en el que intereses y expectativas son alineados, así como la autorregulación con base en la interpretación conveniente de las instituciones. Además, la entidad reguladora también se beneficia al lidiar con un número menor de agentes e intereses. Por fin, cuanto mayores las calidades de importancia del stakeholder, mayores sus oportunidades de proponer cambios institucionales, reduciendo las posibilidades de veto y aumentando la discrecionalidad en la interpretación de las reglas.

Palabras clave: Teoría de Stakeholders. Cambio Institucional Gradual y Transformativo. Agencias Reguladoras. Instituciones.

\section{Introdução}

A implementação de políticas públicas e, mais especificamente, a provisão dos serviços públicos, não são exclusividade do Estado. Como apontam Almeida e Gomes (2019), as políticas públicas são elaboradas no formato de arranjos compostos por inúmeros atores, com diferentes interesses e graus de interdependência. Esses arranjos são estruturas baseadas em um conjunto de instituições, ou seja, leis, regras, normas e resoluções definidas para gerar estabilidade e cooperação entre os agentes (Mahoney \& Thelen, 2010; North, Wallis, \& Weingast, 2009). No Brasil, e em muitos outros países, a implementação de políticas públicas tem se dado por meio de instrumentos que implicam na parceria entre organizações públicas e organizações do setor privado. Um exemplo disso são as parcerias público-privadas (PPPs) ou as redes de políticas públicas (Cabral, Fernandes, \& Ribeiro, 2016; Nederhand \& Klijn, 2016; Ollaik \& Medeiros, 2011; O'Toole, 2015). Assim, muitas vezes, a função do Estado será mais conduzir os processos (steering) do que executá-los (rowing), fiscalizando e regulando o comportamento dos agentes em um sistema de política pública para que os resultados esperados sejam alcançados (Agranoff, 2012).

No contexto brasileiro foram criadas as agências reguladoras a partir de 1996, como parte da reforma do Estado promovida na década de 1990. Nunes, Nogueira, Costa, Andrade e Ribeiro (2007) indicam que a Reforma Gerencial previa uma redefinição do papel do Estado, configurando-se como promotor e regulador. Em tese, os entes reguladores devem possuir autonomia e independência decisória, mas, ao mesmo tempo, inserir os atores interessados, tais como consumidores e investidores, no processo de elaboração de normas regulamentares (Brasil, 1997). Peci (2007) analisa que as agências foram estruturadas de maneira diferenciada do restante da estrutura estatal com o objetivo de mantê-las equidistantes das partes interessadas na regulação. A função regulatória tem entre seus objetivos a promoção da competitividade do mercado regulado, a garantia dos direitos dos consumidores e usuários, e a resolução de conflitos entre as empresas prestadoras de serviços, consumidores e usuários (Brasil, 1997). Atualmente, são onze as agências reguladoras no âmbito federal, que atuam em diversos setores econômicos, interferindo em políticas sociais e políticas voltadas para o meio ambiente.

Nesse sentido, Bispo e Gomes (2018) argumentam que as políticas públicas são guiadas pelos interesses de seus stakeholders, pois eles podem atuar aprovando, influenciando, implementando, monitorando ou ajudando a modificar ações e decisões. Ansell e Gash (2008) sugerem que os stakeholders trabalham coletivamente para estabelecer regras para a provisão de bens públicos, construindo confiança e apoio em negociações para benefício mútuo. Por outro lado, não é certo que todos os atores envolvidos estarão dispostos a cooperar em pleno acordo segundo o arranjo institucional estabelecido. Bundy, Vogel, \& Zachary (2018) propõem que o relacionamento entre uma organização e seus stakeholders pode ser colaborativo ou desajustado, comprometedor e marcado por conflitos.

Para Vieira e Gomes (2014), as instituições são elementos que distribuem recursos e atendem aos interesses daqueles em condição hegemônica. Logo, entende-se ser importante o estudo do comportamento de organizações que buscam provocar mudanças nas instituições em contextos marcados pela regulação do Estado, implementada por meio das entidades reguladoras. Exemplos do fenômeno seriam: empresas de telefonia ou de aviação buscando influenciar a criação e/ou conteúdo de portarias e regulamentos da Agência Nacional de Telecomunicações e da Agência Nacional de Aviação Civil, e os bancos quando buscam mudanças nas normas do Sistema Financeiro Nacional. A competição por um status que Ihes seja mais favorável poderá levar a um processo de mudança institucional, gradual e transformativo, empreendido por agentes insatisfeitos com os objetivos da política ou com a decorrente distribuição de recursos e status. Mas, afinal, como os stakeholders se comportam enquanto agentes de mudança institucional? Como podem conseguir as mudanças que desejam e evitar aquelas que lhes são indesejáveis? E, por fim, quais estratégias irão usar para exercer influência? 
Este trabalho tem como objetivo geral caracterizar o comportamento das organizações que buscam provocar mudança institucional. Para tanto, pretende-se descrever as relações entre as entidades reguladoras e seus stakeholders (também representados em entidades de classe), conjugando modelos de análises de stakeholders com o modelo de mudança institucional gradual e transformativa. Considerando a dinamicidade do ambiente e a decorrente sujeição a mudanças de toda sorte, aí incluídas as mudanças nas "regras do jogo" (North, 1990), ou seja, nas instituições, não se pode supor que elas surjam, se mantenham e se modifiquem exclusivamente por iniciativa da entidade reguladora. Assim, as organizações reguladas, na condição de stakeholders das entidades reguladoras, podem exercer influência no processo de mudança institucional, atuando como agentes de mudança.

Portanto, nesse ponto, há convergência entre os modelos teóricos ora propostos: as organizações reguladas por uma entidade estatal são seus stakeholders, mas são também "seguidores de regras" no regime social descrito por Streeck e Thelen (2005), e posicionam-se como agentes de mudança institucional segundo seus interesses e necessidades, a partir de atributos como: poder normativo, coercitivo e utilitário; legitimidade e urgência de demanda (Mitchell, Agle, \& Wood, 1997). Além disso, Streeck e Thelen (2005) e Mahoney e Thelen (2010) propõem que o tipo de mudança institucional gradual e transformativa é função das características do contexto político e da vulnerabilidade da instituição-alvo, porém acredita-se que, além dessas variáveis, os atributos dos agentes interessados (os stakeholders) e a sua capacidade de articulação também importam.

O presente estudo torna-se relevante enquanto articulação teórica uma vez que situa a discussão sobre a influência de stakeholders segundo um enfoque institucional. Em outras palavras, estabelece como premissa que os comportamentos dos agentes estão sujeitos aos constrangimentos estabelecidos pelas instituições. Entretanto, ao tomar como base uma vertente mais construtivista dentro do novo institucionalismo (Mahoney \& Thelen, 2010; Schmidt, 2008; Vieira \& Gomes, 2014; Vieira, 2019), reconhece a capacidade dos stakeholders de questionarem, confrontarem e transformarem as instituições. O trabalho também se justifica por apresentar para a literatura sobre stakeholders proposições teóricas que iluminam as relações de disputa e competição, enquadrando-os em lutas hegemônicas e contra-hegemônicas. Do ponto de vista do novo institucionalismo, especificamente do modelo de mudança institucional gradual e transformativa, o trabalho pretende trazer um avanço na caracterização dos agentes de mudança institucional (Mahoney \& Thelen, 2010; Streeck \& Thelen, 2005), pois este não se limita a apontar os tipos de papéis exercidos e estratégias adotadas, apontando as suas características e recursos. Do ponto de vista prático, os gestores das organizações podem se beneficiar ao instrumentalizar alguns aspectos propostos no trabalho, tal como a identificação e caracterização dos stakeholders e os tipos de mudança institucional gradual e transformativa, que, por sua vez, poderão guiar a criação de estratégias ligadas à advocacia e ao lobbying. Afinal, o reconhecimento dos jogadores, de suas expectativas e interesses, bem como das regras do jogo, propiciam vantagem competitiva e flexibilidade estratégica.

\section{Modelos de análise de stakeholders}

A literatura sobre stakeholders é relativamente recente, tendo sido desenvolvida a partir do trabalho seminal de Freeman (1984), no qual defende que as empresas deveriam dedicar atenção aos interesses de outros atores, além dos proprietários e do corpo diretivo, nas tomadas de decisões estratégicas. A preocupação principal era explicar a relação de empresas com o ambiente externo e seu comportamento dentro desse ambiente. Segundo Frooman (1999), o modelo continha uma empresa no centro e seus stakeholders em volta, estabelecendo com ela relações tidas como diádicas e mutuamente independentes. Com o tempo, extrapolou-se o modelo para o contexto organizacional, sendo aplicado para qualquer tipo de organização, com qualquer tipo de composição ou contexto histórico (Gomes, Lidlle, \& Gomes, 2010; Phillips, Freeman, \& Wicks, 2003).

Segundo Mainardes, Alves e Raposo (2011), incontáveis definições podem ser encontradas para o termo, mas a maior parte permanece alinhada à definição de Freeman (1984), consistindo na necessidade de se considerar os interesses de quem pode afetar (exercer influência) ou ser afetado (influenciado) pelo escopo dos objetivos organizacionais, ou, ainda, pelas políticas, ações e decisões das organizações na perseguição desses objetivos.

Recentemente, Bryson (2018, p. 42, tradução nossa) definiu o conceito de stakeholder como "qualquer pessoa, grupo ou organização que pode apresentar demandas requerendo a atenção de uma organização ou outra entidade, seus recursos ou seu resultado, ou que é afetado pelos seus resultados". Tal definição traz dificuldades para as organizações que pretendem gerenciar seus stakeholders, uma vez que qualquer pessoa pode se tornar stakeholder, bastando, para isso, apresentar uma demanda.

Nesse contexto, o que poderia fazer uma demanda sobressair-se às demais seria o grau de atenção imediata exigida, ou seja, a percepção de "urgência". Percebe-se, ainda, um viés teórico deontológico nessa definição, tal como em Evan e Freeman (1993), em que os stakeholders possuiriam valor intrínseco e, como tal, deveriam ser tratados como "fins" em si mesmos, e não apenas como "meios" para se chegar aos "fins".

Em contraste, a definição proposta por Eden e Ackermann (2013, p. 117, tradução nossa) apresenta um viés estratégico: "pessoas ou pequenos grupos com o poder de responder à organização, negociar com ela e mudar seu futuro estratégico". Portanto, o "poder" seria o atributo necessário e suficiente para se considerar uma parte 
interessada como stakeholder. Logo, as demandas e interesses dos atores de maior "poder" seriam objeto de maior atenção e, portanto, exerceriam maior influência no processo decisório organizacional.

Por outro lado, Donaldson e Preston (1995) buscaram integrar os dois aspectos. Para eles, stakeholders são quaisquer partes que possuam interesses legítimos nas atividades de uma organização, desde que tal organização também possua interesse em manter o relacionamento com essas partes. Além disso, uma vez que a "legitimidade" seria o atributo necessário e suficiente para que uma determinada parte fosse considerada um stakeholder, essa parte deveria ser considerada por sua própria causa, e não porque seus interesses se alinham aos da organização ou de outro grupo associado. Portanto, segundo essa definição, existe a precondição de reciprocidade do interesse na manutenção dos relacionamentos para que uma organização reconheça as partes interessadas como stakeholders, mas também se aponta o dever ético ou moral de reconhecer os stakeholders que possuam legitimidade.

Mitchell et al. (1997), por sua vez, apresentaram um modelo de classificação que causou impacto na forma como se define um stakeholder. Afinal, os atributos "poder", "legitimidade" e "urgência", isoladamente, não são suficientes para se identificar as partes interessadas de maior relevância, de forma a indicar a que stakeholders uma organização deveria priorizar. Desse modo, esses três atributos acumuláveis e socialmente construídos são combinados entre si, gerando oito possibilidades de classificação. Os stakeholders que acumulam os três atributos são classificados como "definitivos"; os que possuem poder e legitimidade são "dominantes"; os que possuem poder e urgência são "perigosos"; os que possuem legitimidade e urgência são "dependentes". Aqueles que possuem apenas poder são "dormentes"; apenas legitimidade, "discricionários", e apenas urgência, são stakeholders "demandantes". Aqueles que não possuírem nenhum dos atributos não são considerados stakeholders.

Preble (2005) interpreta Agle, Mitchell e Sonnenfeld (1999) e define "poder" como a habilidade de influenciar o comportamento de uma organização, independentemente da legitimidade ou não da demanda. "Legitimidade" seria o embasamento contratual, legal ou moral dessa demanda ou se a demanda é socialmente aceitável. "Urgência" seria o grau de atenção imediata que a demanda necessita, o que seria um componente dinâmico adicionado à análise de relevância e à gestão de stakeholders.

Diversos estudos recentemente publicados no Brasil têm se dedicado a investigar o comportamento dos stakeholders. Miragaia, Ferreira e Ratten (2017) analisaram a influência de stakeholders na gestão de clubes desportivos sem fins lucrativos. Os autores propõem que a gestão eficiente dessas entidades requer a identificação de seus principais stakeholders e dos meios para interagir com eles para melhorar a gestão sobre recursos materiais, humanos e financeiros. Para os autores, "os stakeholders de uma organização podem assumir diferentes configurações e podem ser apenas indivíduos ou grupos específicos de indivíduos com objetivos semelhantes" (Miragaia et al. 2017, p. 46). Já Pagnussatt, Petrini, Silveira e Santos (2018) estudaram os stakeholders envolvidos em pequenas centrais hidrelétricas. Além de os identificarem, apontaram a falta de diálogo e colaboração no momento de tomada de decisões, levando à falta de informação e perda de confiança entre eles. Os autores sugerem que a gestão ativa do ambiente de negócio, as relações entre os diferentes grupos e a promoção de interesses compartilhados podem levar à sobrevivência da organização ou da política no longo prazo.

Cabral et al. (2016) analisaram os papéis dos stakeholders na implementação de parcerias públicoprivadas, no estado da Bahia, nas áreas de saneamento, saúde e esporte/cultura. Mais especificamente, os autores buscaram fornecer uma visão sobre como os distintos grupos de stakeholders atuam em arranjos organizacionais inovadores no âmbito das políticas públicas. Eles apontam que, por meio de PPP, stakeholders, atuando isoladamente ou em conjunto, podem formular projetos, atrair parceiros, viabilizar sua execução e influenciar na entrega e controle de bens públicos por meio de atores privados. Brandão, Diógenes e Abreu (2017) investigaram a relação entre as práticas de responsabilidade social corporativa para o stakeholder funcionário e a competitividade dos bancos no Brasil, apontando um impacto em seu desempenho financeiro. Os autores também mencionam o trabalho de Harrison e Wicks (2013), que define o sistema de criação de valor, no qual os stakeholders fornecem recursos ou influência em troca de retornos materiais e/ou intangíveis, resultando em um compartilhamento de valor mutuamente benéfico.

Bispo e Gomes (2018) mapearam os stakeholders envolvidos na formulação do Programa Nacional de Acesso ao Ensino Técnico e Emprego (Pronatec) buscando compreender sua atuação e influência no processo. Os autores argumentam que as políticas públicas são guiadas pelos interesses de seus stakeholders e que os diversos sujeitos interessados no Pronatec discutiram e negociaram os seus interesses constituindo um ambiente de relações contraditórias e estruturalmente articuladas. Abreu e Gomes (2018) procuraram formas de medir a influência colaborativa dos stakeholders e das ações de orçamento aberto indicando ser necessário o estabelecimento de regras claras para a construção de um ambiente de confiança e cooperação. Neto e Borges (2019) buscaram analisar as mudanças, permanências e tensões nas narrativas dos stakeholders enquanto práticas estratégicas no contexto da mineração. Os autores lançam luz sobre o papel das tensões relacionais que atuam como elementos facilitadores e dificultadores nas interações entre os grupos de stakeholders. Observaram uma competição para definir a narrativa dominante que pode determinar o futuro das organizações e da atividade produtiva de mineração.

Em relação à análise de stakeholders, é preciso ressalvar que, como coloca Vieira (2017), tanto os papéis desempenhados pelos stakeholders quanto as percepções envolvendo a relevância de suas demandas são voláteis, dependentes do contexto, da ação do tempo e dos momentos de interação com outros stakeholders. Então, qualquer 
modelo deverá exigir um esforço contínuo das organizações, tanto para entender os personagens reais e concretos e suas circunstâncias (Freeman \& Mcvea, 2001) quanto para atribuir maior ou menor relevância às suas demandas, pois são influenciadas exatamente pela realidade e pelas circunstâncias que envolvem esses personagens, por isso são dinâmicas, latentes e difíceis de discernir (Voss, Voss, \& Moorman, 2005). Em suma, um ator, enquanto stakeholder, pode assumir mais de um papel, e não é possível determinar se novos papeis irão surgir no decorrer do tempo ou não. Logo, qualquer classificação de partes interessadas deve ser provisória, na melhor das hipóteses (Cabral et al., 2016). Não obstante, analisando a atuação de stakeholders no âmbito de governos locais, Gomes et al. (2010) propuseram uma classificação conforme o tipo de papel que exercem: reguladores, colaboradores, definidores da agenda, controladores e legitimadores. Por sua vez, Ribeiro e Costa (2017) também argumentam, em estudo empírico, que os stakeholders exercem influência na gestão e no controle das organizações desportivas.

A partir dessas observações e tendo em vista que os stakeholders atuam pautados por um conjunto de instituições, entre as quais normas regulamentadoras, são elaboradas as seguintes proposições teóricas:

- Proposição teórica 1: em um ambiente institucional, com a presença de agências reguladoras, os seus stakeholders podem se associar para ampliar o diálogo, a confiança e a geração de valor, tornando menos desigual a relação com a entidade reguladora;

- Proposição teórica 2: a criação e o compartilhamento de valor entre os stakeholders se dá em função da percepção e do posicionamento que desenvolvem frente ao contexto institucional no qual operam;

- Proposição teórica 3: não apenas relações de cooperação serão observadas, pois as tensões relacionais entre stakeholders e instituições são inerentes ao contexto de políticas públicas, gerando disputas pela condição hegemônica.

\section{Instituições e a mudança institucional gradual e transformativa}

Muitas das definições existentes sobre instituições ressaltam aspectos ligados à estabilidade, continuidade e reprodução. Por exemplo, Scott (1995) as define como estruturas que propiciam estabilidade e sentido ao comportamento das organizações. De acordo com o autor, as instituições seriam duradouras, simbólicas, resistentes à mudança e transmitidas entre as gerações pela manutenção e reprodução. Além disso, seriam suportadas por três pilares igualmente fundamentais: o regulador (as instituições estabelecem regras e inspecionam a conformidade, regulando o comportamento); o normativo (incluem valores e normas, definem objetivos e metas e os caminhos para alcançá-los) e o cognitivo (preocupam-se com os processos interpretativos internos dos atores sobre a natureza da realidade social e o compartilhamento dessas percepções).

Corroborando essa noção de perenidade, Powell (1991, p. 197, tradução nossa) argumenta que "coisas institucionalizadas tendem à inércia, isto é, resistem aos esforços de mudança”, ao passo que Jepperson (1991, p. 145 , tradução nossa) propõe que as "instituições são padrões sociais que, quando cronicamente reproduzidos, devem sua sobrevivência a processos relativamente auto-ativados". Ainda nessa direção, Peci, Vieira e Clegg (2006) apontam uma tendência à homogeneidade: o processo de institucionalização ocorre quando convenções sociais assumem status de regra como consequência da adequação ao sistema de valores de uma sociedade e pelo temor pelo que pode acontecer caso se desvie das prescrições de como se deve agir, o que se deve ou não fazer.

Em contrapartida, para North (1990, 1999), as organizações são players de um "jogo", e, assim como perseguem seus objetivos, atuam como agentes de mudança institucional. A metáfora de "jogo" foi utilizada por North (1990, p. 3 , tradução nossa) para se referir às instituições como "regras do jogo em uma sociedade" ou, mais formalmente, "restrições criadas pelo próprio homem para ditar os contornos da interação humana". Com um viés econômico, atribui o processo de institucionalização a dois fatores principais: às "incertezas", tanto pela limitação da racionalidade dos agentes e da capacidade computacional quanto pela natureza dinâmica do ambiente; e dos "custos de transação", tanto pela dificuldade dos agentes em conhecer de fato o objeto da transação em andamento quanto pela necessidade de assegurar a legitimidade de transações de troca (North, 1990, 1999).

Todavia o sistema de valores da sociedade que deu origem às instituições não é estático, pois existem agentes sociais em diálogo e em ação, exercendo influência no modo como os outros interpretam o ambiente à sua volta e as regras vigentes (Schmidt, 2008). Além disso, refletindo sobre Peci et al. (2006), as percepções sobre "certo" e "errado", sobre como se deve agir e o que se deve ou não fazer, vão se modificando paulatinamente na sociedade mediante o curso dos acontecimentos. Em outras palavras, os termos "homogeneidade" e "estabilidade", em relação às instituições, em vez de serem interpretados como sinônimo de "rigidez" indicariam que as instituições podem ser objeto de mudanças não disruptivas, ainda preservando uma relativa estabilidade institucional (Mahoney \& Thelen, 2010; Streeck \& Thelen, 2005). Não se pode ignorar, também, o fato de que as organizações buscam influenciar as percepções dentro da sociedade e os critérios dessa apreciação, oferecendo novas interpretações e entendimentos que Ihes sejam mais favoráveis e acabem, dessa forma, por legitimar suas ações.

De modo complementar, segundo Scott (1995), as organizações, enquanto partes de um sistema social, necessitam de mais que recursos físicos e informacionais: elas dependem também de legitimidade. Para Rossoni e 
Machado-da-Silva (2013), o julgamento, a aceitação e a credibilidade junto aos stakeholders condicionam a capacidade de adquirir recursos, uma vez que as organizações fazem parte de um sistema social no qual impera um conjunto de crenças, valores e pressupostos compartilhados. Hall e Taylor (1996) apresentam três perspectivas institucionais constituintes do que se denomina "novo institucionalismo" em busca de respostas a três perguntas: como os atores se comportam, o que fazem as instituições, por que as instituições se mantêm? Todavia não perguntam como as instituições se modificam ao longo do tempo.

No novo institucionalismo histórico entende-se que a estrutura institucional da comunidade política dita o comportamento coletivo. No novo institucionalismo sociológico a cultura influencia na estruturação institucional e no comportamento coletivo. No novo institucionalismo da escolha racional cada indivíduo busca consolidar nas instituições o melhor cenário para atender aos seus interesses e acaba chegando a um acordo voluntário com os demais atores, muitas vezes alcançando um resultado subótimo. As três perspectivas, afinal, enxergam uma tendência à estabilidade institucional e à sua reprodução. Vieira e Gomes (2014, p. 682) sugerem que nessas abordagens predomina a noção de que "no conflito entre estrutura e agência, a balança pende para a estrutura". Bell (2011) argumenta no mesmo sentido, ou seja, a importância da ação dos agentes e de sua discricionariedade não é adequadamente abordada nesse viés teórico.

Como lembra Coraiola, Jacometti, Baratter e Gonçalves (2015, p. 702), até certo tempo, os estudos organizacionais com abordagem institucional focavam em uma explicação parcial, "privilegiando o estudo da influência e do controle das instituições sociais sobre as práticas organizacionais e o funcionamento das organizações". Ainda segundo os mesmos autores, DiMaggio (1988) já buscava estudar a influência dos agentes na explicação da mudança institucional, seguido por uma série de autores, tais como: Lawrence e Phillips (2004), Greenwood e Suddaby (2006), Koene (2006), Leca e Nacache (2006), Hardy e Maguire (2008), quase todos anteriores ou contemporâneos aos trabalhos de Streeck e Thelen (2005) e Mahoney e Thelen (2010).

Streeck e Thelen (2005) e Mahoney e Thelen (2010) defendem a perspectiva de que as instituições estão em constante mudança gradual e transformativa. Como contraponto à ênfase de algumas teorias na estabilidade institucional e nas mudanças abruptas de natureza exógena, tal como a teoria do equilíbrio pontuado, os autores argumentam que até mesmo eventuais períodos de estabilidade institucional são frutos de um esforço contínuo dos atores que a defendem. Muito embora não neguem a ocorrência de choques exógenos ou de momentos de ruptura, procuram romper com uma visão estática das instituições, na qual a estrutura prevalece, reconhecendo a força transformadora da agência.

Streeck e Thelen (2005, pp. 12-13, tradução nossa) situam as instituições como "regimes sociais": são conjuntos de regras que estipulam o comportamento esperado dos atores sociais. A legitimidade dos regimes sociais depende da sua conformidade com as expectativas, princípios e valores da sociedade na qual as instituições estão inseridas. Em um regime social, diferenciam-se partes de um relacionamento contínuo: de um lado, situam-se os "criadores de regras" e, de outro, os "seguidores de regras". Entre eles, o foco de sua ação, ou seja, as regras propriamente ditas; em torno deles, a terceira parte diversa e a sociedade em geral.

Streeck e Thelen (2005) e Mahoney e Thelen (2010) propuseram quatro tipos de mudança institucional gradual e transformativa, cada uma com a predominância de um determinado tipo de ator institucional, empreendendo uma estratégia de mudança mais provável ao cenário. Os tipos de atores interessados em mudanças institucionais variam conforme as possibilidades de uma proposta de mudança ser vetada e o nível de discricionariedade na interpretação das normas vigentes e na implementação de novas normas ou de normas alteradas (Figura 1).

Figura 1. Tipos de mudança institucional e de agentes de mudança.

\begin{tabular}{|c|c|c|c|}
\cline { 3 - 4 } & & \multicolumn{2}{|c|}{ Características da Instituição-Alvo } \\
\cline { 3 - 4 } & $\begin{array}{c}\text { Baixo nível de } \\
\text { discricionariedade na } \\
\text { interpretação / } \\
\text { implementação } \\
\text { (enforcement })\end{array}$ & $\begin{array}{c}\text { Alto nível de } \\
\text { discricionariedade } \\
\text { na interpretação / } \\
\text { implementação } \\
\text { (enforcement })\end{array}$ \\
\hline \multirow{2}{*}{$\begin{array}{c}\text { Características } \\
\text { do contexto } \\
\text { político }\end{array}$} & $\begin{array}{c}\text { Muitas } \\
\text { possibilidades } \\
\text { de veto }\end{array}$ & $\begin{array}{c}\text { Mudança incremental } \\
\text { (layering }) ; \\
\text { predominância de atores } \\
\text { subversivos }\end{array}$ & $\begin{array}{c}\text { Mudança pela } \\
\text { negligência (drift }) ; \\
\text { predominância de } \\
\text { atores parasitas } \\
\text { simbióticos }\end{array}$ \\
\cline { 3 - 5 } & $\begin{array}{c}\text { Poucas } \\
\text { possibilidades } \\
\text { de veto }\end{array}$ & $\begin{array}{c}\text { Mudança por } \\
\text { substituição } \\
\text { (displacement }) ; \\
\text { predominância de atores } \\
\text { insubordinados / } \\
\text { opositores }\end{array}$ & $\begin{array}{c}\text { Mudança pela } \\
\text { conversão; } \\
\text { predominância de } \\
\text { atores oportunistas }\end{array}$ \\
\hline
\end{tabular}

Fonte: Elaborado pelos autores a partir de Mahoney e Thelen (2010). 
A mudança por displacement ocorre por meio de remoção de regras existentes e a introdução de novas. Costuma ocorrer em ambiente que apresenta poucas possibilidades de veto, ou seja, as instâncias que podem impedir ou atrasar o processo são poucas ou possuem pouco poder. Por outro lado, apresenta pouca possibilidade de interpretações alternativas das regras ou de sua implementação. Com o ambiente institucional favorável, os agentes adotam a estratégia de propor substituição das regras, agindo abertamente contra o status quo, e são denominados "opositores" ou "insurgentes".

A mudança do tipo layering ocorre por meio de inserção de novas regras ao conjunto pré-existente, de emendas ou de revisões de regras antigas. O ambiente institucional se apresenta adverso: muitas possibilidades de veto e pouca discricionariedade na interpretação e implementação de regras. Por isso, os atores preferem dissimular suas intenções e propõem mudanças incrementais no lugar de mudanças mais impactantes, para evitar os custos do embate com os defensores do status quo.

Já a mudança do tipo drift ocorre pela alteração do impacto das regras existentes em decorrência de mudanças no ambiente, que apresenta alta discricionariedade para interpretar e implementar as regras, mas muitas instâncias de veto para novas regras, ou instâncias com muito poder de veto. Os atores, então, agem no sentido de minar a instituição no longo prazo. Vale advertir que existem também atores simbióticos, não constantes da Figura 1, que tendem a defender o status quo, não defendendo mudanças e não minando as instituições.

A mudança do tipo conversion ocorre por meio da alteração da forma de se aplicar as regras já existentes, em função de um realinhamento estratégico. Ocorre em ambientes em que as regras podem ser reinterpretadas e as mudanças possuem poucas possibilidades de veto. Os atores preferem agir de forma ambígua, temendo os custos do claro posicionamento e explorando as oportunidades que surgirem.

O modelo de Mahoney e Thelen (2010) apresenta quatro possibilidades de comportamento dos agentes de mudança conforme duas variáveis com apenas dois valores possíveis: possibilidades de veto altas ou baixas e discricionariedade alta ou baixa. Contudo não leva em consideração a existência de agentes de mudança (stakeholders) mais relevantes que outros. Talvez as possibilidades de veto e a discricionariedade na interpretação sejam variáveis sensíveis à relevância dos agentes. Assim, a possibilidade de veto da proposição do agente " $A$ " pode se verificar menor do que a possibilidade de veto da proposição do agente "B". Nesse diapasão, parece fazer sentido analisar os agentes de mudança mediante algum critério de atribuição de relevância, como aquele apresentado por Mitchell et al. (1997).

A partir da discussão feita sobre as instituições e o modelo de mudança institucional gradual e transformativa, é possível elaborar as seguintes proposições teóricas:

- Proposição teórica 4: os stakeholders não apenas seguem as regras, mas podem atuar isoladamente ou em associação (como em entidades de classe), posicionando-se como agentes de mudança institucional;

- Proposição teórica 5: os atributos "poder", "legitimidade" e "urgência de demanda" trazidos pelos stakeholders que atuam associados podem aumentar a probabilidade de veto e o grau de discricionariedade na interpretação das regras propostas pela entidade reguladora, gerando mudança institucional dos tipos drift, layering, conversion e displacement.

\section{Stakeholders e mudança institucional em ambientes de regulação do Estado}

Em um cenário no qual as organizações reguladas buscam mudar as instituições, influenciando, por exemplo, a elaboração de normas regulamentares, existe a possibilidade de, por meio da cooperação e compartilhamento de atributos, estruturarem um sistema de criação de valor (Harrison \& Wicks, 2013), estabelecendo um maior equilíbrio de forças com a entidade reguladora.

Esforços de cooperação desse tipo são comuns e costumam ser formalizados por meio de entidades de classe, associações empresariais, federações e confederações, em setores como o da indústria, da agricultura, do turismo e outros serviços. Nesse sentido, sugere-se que uma associação formal entre stakeholders torna-se ela própria um stakeholder do tipo "definitivo", segundo Mitchell et al. (1997), pois incorpora o poder, a legitimidade e a urgência de seus associados. Assim, espera-se que o poder e a legitimidade possam ajudar a aumentar a probabilidade de veto e aumentar o grau de discricionariedade na interpretação das regras. Por conseguinte, a urgência das demandas de um stakeholder legítimo e poderoso pode reduzir o número de instâncias de veto das suas proposições.

Outra consequência esperada da representação por meio de entidades de associação seria a apresentação de demandas criadas coletivamente, como um desdobramento do sistema de criação de valor (Harrison \& Wicks, 2013). No âmbito das entidades de classe, as organizações debatem os temas de seu interesse sem a interferência do Estado e, democraticamente, podem chegar a um resultado sobre quais demandas apresentar, de que forma apresentá-las e em que momento. Esse procedimento dificulta que o Estado, a imprensa e a opinião pública conheçam os conflitos, divergências e rivalidades entre as organizações associadas. O processo interno de criação de demandas remete à perspectiva da escolha racional apontada por Hall e Taylor (1996), uma vez que cada organização busca consolidar, nas demandas por mudanças institucionais, o melhor cenário para atender aos seus interesses e acaba chegando a 
um acordo voluntário com os demais atores, gerando, por vezes, um resultado subótimo. Um efeito colateral desse processo é o surgimento de novas entidades representantes de categorias dentro dessa coletividade, que almejam melhores resultados. Como apontam Pagnussatt et al. (2018), Bispo e Gomes (2018) e Neto e Borges (2019), a cooperação entre stakeholders não é automática, pois existem interesses e expectativas distintas.

- Proposição teórica 6: a entidade formal em que os stakeholders se associam também consiste em uma arena na qual eles dialogam e ajustam seus interesses e expectativas.

Além disso, uma terceira consequência relacionada às entidades de associação seria a autorregulação. Essas entidades podem interpretar as instituições vigentes, identificar lacunas e editar normas e procedimentos aplicáveis aos seus associados que visam a explorar e complementar as regras instituídas pela entidade reguladora. As organizações representadas passam a utilizar essas normas e procedimentos juntamente com o regramento original criado externamente, todavia a autorregulação carrega consigo uma interpretação desse regramento conforme os interesses da classe, pressupondo, para isso, um ambiente com alto nível de discricionariedade. Revela-se, também, como uma tentativa de evitar apresentar uma demanda por mudança, do tipo displacement ou layering (Mahoney \& Thelen, 2010), devido às possibilidades de veto que podem se fazer presentes principalmente a partir da entidade reguladora. Portanto, tratar-se-ia de uma estratégia de agentes do tipo "simbióticos parasitas", com o potencial de minar as instituições no longo prazo. Assim, um conjunto de regramentos internos é construído ao longo do tempo, competindo com a regulação original imposta pela entidade reguladora, até o ponto em que as organizações pouco se refiram a ela, provocando sua revisão ou substituição.

- Proposição teórica 7: as entidades de classe exercem autorregulação uma vez que interpretam as instituições, identificam lacunas e passam a editar normas e procedimentos aplicáveis aos seus associados, traduzindo e complementando as regras instituídas pela entidade reguladora.

Do ponto de vista da entidade reguladora, essa representação por entidades de classe é bem-vinda, porque permite o gerenciamento dos relacionamentos institucionais, reduzindo-os da ordem de milhares para unidades ou dezenas e também porque as tratativas com as entidades de associação, obrigatoriamente, repercutirão para todos os regulados. Além disso, deixa de se preocupar com divergências, conflitos de interesse e de opinião das organizações reguladas, pois as demandas oriundas das entidades de classe já são fruto da superação de todas essas questões ou, ao menos, são subscritas pelas organizações reguladas. Finalmente, as mudanças institucionais resultantes da influência das entidades de classe carregam consigo o status de coisa negociada e aceita, portanto, há maior probabilidade de que sejam cumpridas sem maiores questionamentos.

- Proposição teórica 8: a entidade reguladora se beneficia da representação de seus stakeholders por meio de entidades de associação, porque: otimiza a quantidade de relacionamentos que precisará gerenciar; as demandas oriundas das entidades de associação já consolidaram divergências e interesses e são subscritas pelas organizações reguladas; e as mudanças institucionais resultantes da atuação das entidades de associação carregam o status de coisa negociada, havendo, portanto, maior probabilidade de que sejam cumpridas pelos stakeholders regulados.

Outra estratégia derivada da atuação de stakeholders seria a criação de mais de uma entidade de associação. Além de uma entidade de associação principal, que representa uma categoria inteira e carrega todo o somatório dos atributos, outras entidades secundárias representariam categorias e subcategorias dentro do mesmo conjunto de organizações, sendo atribuída a elas parte da relevância atribuída à entidade de classe principal.

Na prática, cada organização regulada se associaria a mais de uma entidade, multiplicando sua influência sem, necessariamente, ter de investir no aumento de seus atributos. Essas entidades de associação secundárias passam também a exercer papel de stakeholders e de agentes de mudança, tanto perante a entidade reguladora quanto perante a entidade de associação principal. Perante o regulador, pode apoiar o posicionamento da entidade de associação principal, porém procura dar voz a demandas específicas da categoria que representa. Perante a entidade de associação principal, defende os interesses da categoria no processo de criação de demandas coletivas. Assim, a representação pode atingir dois ou três níveis, multiplicando-se a percepção acerca da relevância das organizações e tornando o ambiente cada vez mais complexo.

- Proposição teórica 9: além das entidades de associação principais, dotadas de maior poder, legitimidade e urgência, vislumbra-se a existência de entidades de associação secundárias, que passam também a exercer papel de stakeholders e de agentes de mudança no lugar de seus representados, tanto perante a entidade reguladora quanto perante a entidade de classe principal. 


\section{Considerações Finais}

Neste trabalho discutiu-se como as organizações sujeitas à regulação do Estado por meio de entidades reguladoras reagem ao conjunto de instituições quando não satisfeitas com determinando status quo. Organizações públicas ou privadas podem provocar mudança institucional de modo que os seus interesses sejam contemplados. Portanto, embora as instituições tenham um caráter perene (Powell, 1991) e haja estruturas que regulam comportamento e distribuem recursos (North et al., 2009), provendo significado e estabilidade (Scott, 1995), estão sujeitas a serem reinterpretadas (Schmidt, 2008) e confrontadas (Mahoney e Thellen, 2010; Vieira \& Gomes, 2014; Vieira, 2019) pelos stakeholders regulados.

Nesse sentido, as entidades reguladoras são consideradas as "guardiãs" das instituições ou, em outras palavras, "criadoras de regras". Ao mesmo tempo, as organizações reguladas configuram-se como seus stakeholders e também como "seguidores de regras", exercendo diferentes papéis, caracterizados com diferentes graus de relevância e possivelmente engajados em processos de mudança institucional gradual e transformativa. Assim, sugere-se que os stakeholders, dotados de atributos tais como poder (coercitivo, normativo e utilitário, por exemplo), legitimidade e urgência de demandas, assumem também a condição de agentes de mudança institucional.

Ao analisar a relação entre entidades reguladoras e organizações reguladas num contexto institucional sujeito a mudanças transformativas, foram estabelecidas algumas proposições teóricas sujeitas à análise empírica em estudos futuros. Em linhas gerais, propõe-se que essa configuração tende a beneficiar tanto as organizações reguladas quanto as entidades reguladoras. Além disso, sugere-se que não só as características do contexto político e a vulnerabilidade das instituições importam, mas também as características dos agentes de mudança institucional e sua capacidade de coordenação. Afinal, os atributos poder, legitimidade e urgência influenciariam no grau de discricionariedade na interpretação das regras e nas instâncias de veto. Caberia, portanto, investigar, por meio de estudos empíricos, em que condições os diferentes tipos de mudança institucional se dão, levando-se em conta a composição de tais variáveis.

Um exemplo bem específico de pesquisa empírica que poderia examinar as proposições teóricas aqui definidas seria o caso do Banco Central do Brasil, que propôs a normatização da responsabilidade socioambiental no setor financeiro nacional por meio de consulta pública. Outro exemplo específico seria o caso d a Agência Nacional de Vigilância Sanitária, que decidiu pela proibição do agrotóxico carbofurano num processo que incluiu a realização de uma consulta pública. Além disso, outros estudos podem averiguar:

- A elaboração de métodos de medição e comparação dos atributos de relevância dos stakeholders ao longo do tempo e de medição das variáveis relativas ao ambiente institucional;

- A condução de pesquisas longitudinais de acompanhamento de comportamentos, ações e demandas de agentes de mudança;

- A realização de estudos de caso que permitam verificar a capacidade de resistência da entidade reguladora frente aos esforços de mudança institucional de seus stakeholders.

Em contraponto, é preciso reconhecer que, neste trabalho, algumas questões ligadas ao novo institucionalismo não foram suficientemente abordadas. Por exemplo, Olson (1965) argumenta que existiria uma tendência de contradição entre as ações coletivas e a racionalidade das ações individualizadas, ou seja, a menos que determinado grupo seja pequeno ou haja instrumentos coercitivos que façam os indivíduos (ou organizações) agirem na direção do interesse comum, estes irão agir segundo seus interesses particulares em detrimento dos interesses comuns. Essa visão é conhecida como "tese da contribuição zero" (Ostrom, 2014). Se essa tese for assumida como premissa, faria todo o sentido para os agentes tentarem agir por fora do grupo, caracterizando os free-riders e forçando as organizações a reforçarem suas estruturas de governança para monitorar as ações umas das outras (Ostrom, 2014). Essa discussão é importante, pois o escopo do trabalho examina justamente esforços coletivos de grupos de stakeholders. Desse ponto, surgem lacunas a serem respondidas, como de que forma as entidades de associação lidam com os problemas de ação coletiva referentes ao comportamento de seus filiados e de que maneira os processos de mudança institucional gradual e transformativa são afetados pelos comportamentos egoístas de determinados agentes de mudança institucional.

\section{Referências}

Abreu, W. M., \& Gomes, R. C. (2018). Medindo o nível da influência colaborativa dos stakeholders e das ações de orçamento aberto. Revista de Administração Pública, 52(4), 593-609. https://doi.org/10.1590/0034-7612173451

Agle, B. R., Mitchell, R. K., \& Sonnenfeld, J. A. (1999). Who matters to Ceos? An investigation of stakeholder attributes and salience, corpate performance, and Ceo values. Academy of management journal, 42(5), 507525. https://doi.org/10.5465/256973

Agranoff, R. (2012). Collaborating to Manage: a Primer for the Public Sector. Washington: Georgetown University Press. 
Almeida, L. A., \& Gomes, R. C. (2019). Perspectivas teóricas para análises de políticas públicas: Como lidam com a complexidade? Administração Pública e Gestão Social, 11(5), 16-27. https://doi.org/10.21118/apgs.v11i1.1557

Ansell, C., \& Gash, A. (2008). Collaborative governance in theory and practice. Journal of Public Administration Research and Theory, 18(4), 543-571. https://doi.org/10.1093/jopart/mum032

Bell, S. (2011). Do we really need a new 'constructivist institutionalism' to explain institutional change? British Journal of Political Science, 41(4), 883-906. https://doi.org/10.1017/S0007123411000147

Bispo, F. C. S., \& Gomes, R. C. (2018). The role of stakeholders in the formulation of pronatec. Revista de Administração Publica, 52(6), 1258-1269. https://doi.org/10.1590/0034-761220180095

Brandão, I. F., Diógenes, A. S. M., \& Abreu, M. C. S. (2017). Alocação de valor ao stakeholder funcionário e o efeito na competitividade do setor bancário. Revista Brasileira de Gestao de Negocios, 19(64), 161-179. https://doi. org/10.7819/rbgn.v0i0.3199

Brasil. (1997). Construção do marco legal dos entes reguladores. Recomendação de 31 de maio de 1996 [Cadernos MARE de Reforma do Estado, nº]. Brasília: MARE.

Bryson, J. M. (2018). Strategic planning for public and nonprofit organizations: A guide to strengthening and sustaining organizational achievement. New Jersey, EUA: John Wiley \& Sons.

Bundy, J., Vogel, R. M., \& Zachary, M. A. (2018). Organization-stakeholder fit: A dynamic theory of cooperation, compromise, and conflict between an organization and its stakeholders. Strategic Management Journal, 39(2), 476-501. https://doi.org/10.1002/smj.2736

Cabral, S., Fernandes, A. S. A., \& Ribeiro, D. B. C. (2016). Os papéis dos stakeholders na implementação das parcerias público-privadas no estado da Bahia. Cadernos EBAPE. BR, 14(2). http://dx.doi.org/10.1590/1679$\underline{395147398}$

Coraiola, D. M., Jacometti, M., Baratter, M. A., \& Gonçalves, S. A. (2015). Conciliando agência e contexto na dinâmica da mudança institucional. Cadernos EBAPE. BR, 13(4), 701-726. https://dx.doi.org/10.1590/1679$\underline{39518879}$

DiMaggio, P. (1988). Interest and agency in institutional theory. In L. Zucker (Ed), Institutional patterns and organizations: Culture and environment (pp.3-21). Ballinger Publishing, Massachusetts.

Donaldson, T., \& Preston, L. E. (1995). The stakeholder theory of the corporation: Concepts, Evidence, and Implications. Academy of Management, 20(1), 65-91. https://doi.org/10.5465/AMR.1995.9503271992

Eden, C., \& Ackermann, F. (2013). Making strategy: The journey of strategic management. London: Sage.

Evan, W. M, \& Freeman, R. E. (1993). A Stakeholder Theory of the Modern Corporation: Kantian Capitalism. In T. Beauchamp \& N. E. Bowie (Eds.), Ethical Theory and Business (pp. 75-84). Englewood Cliffs, CA: Prentice Hall.

Freeman, R. E. (1984). Strategic management: A stakeholder approach. Boston, MA; Pitman.

Freeman, R. E., \& Mcvea, J. (2001). A Stakeholder Approach to Strategic Management. The Blackwell handbook of strategic management, 183-201. https://doi.org/10.1111/b.9780631218616.2006.00007.x

Frooman, J. (1999). Stakeholder Influence Strategies. Academy of management review, 24(2), 191-205. https://doi. org/10.5465/AMR.1999.1893928

Gomes, R. C., Liddle, J., \& Gomes, L. O. M. (2010). A five-sided model of stakeholder influence: A cross-national analysis of decision making in local government. Public Management Review, 12(5), 701-724. https://doi. org/10.1080/14719031003633979

Greenwood, R., \& Suddaby, R. (2006). Institutional entrepreneurship in mature fields: The big five accounting firms. Academy of Management journal, 49(1),27-48. https://doi.org/10.5465/AMJ.2006.20785498 
Hall, P. A., \& Taylor, R. C. R. (1996). Political science and the three new institutionalisms. Political studies, 44(5), 936-957. https://doi.org/10.1111/j.1467-9248.1996.tb00343.x

Hardy, C., \& Maguire, S. (2008). Institutional entrepreneurship. In R. Greenwood, C. Oliver, T. B. Lawrence \& R. R. Meyer (Ed), The Sage handbook of organizational institutionalism (pp.198-217). London: Sage.

Harrison, J. S., \& Wicks, A. C. (2013). Stakeholder theory, value, and firm performance. Business Ethics Quarterly, 23(1), 97-124. https://doi.org/10.5840/beq20132314

Jepperson, R. (1991). Institutions, institutional effects, and institutionalism. The New Institutionalism in Organizational Analysis, 6, 143-163.

Koene, B. A. S. (2006). Situated human agency, institutional entrepreneurship and institutional change. Journal of Organizational Change Management, 19(3), 365-382. https://doi.org/10.1108/09534810610668364

Lawrence, T. B., \& Phillips, N. (2004). From moby dick to free willy: Macro-cultural discourse and institutional entrepreneurship in emerging institutional fields. Organization, 11(5), 689-711. https://doi. org/10.1177/1350508404046457

Leca, B., \& Naccache, P. (2006). A critical realist approach to institutional entrepreneurship. Organization, 13(5), 627-651. https://doi.org/10.1177/1350508406067007

Mahoney, J., \& Thelen, K. (Eds.). (2010). Explaining institutional change: Ambiguity, agency, and power. New York: Cambridge University Press.

Mainardes, E. W., Alves, H., \& Raposo, M. (2011). Stakeholder theory: Issues to resolve. Management Decision, 49(2), 226-252. https://doi.org/10.1108/00251741111109133

Miragaia, D. A. M., Ferreira, J. J. M., \& Ratten, V. (2017). O envolvimento estratégico de stakeholders na eficiência das organizações desportivas sem fins lucrativos: de uma perspectiva de sobrevivência para a sustentabilidade. BBR. Brazilian Business Review, 14(1), 42-58. https://dx.doi.org/10.15728/bbr.2017.14.1.3

Mitchell, R. K., Agle, B. R., \& Wood, D. J. (1997). Toward a theory of stakeholder identification and salience: Defining the principle of who and what really counts. Academy of Management Review, 22(4), 853-886. https://doi. org/10.5465/AMR.1997.9711022105

Nederhand, J., \& Klijn, E. H. (2016). Stakeholder involvement in public-private partnerships: Its influence on the innovative character of projects and on project performance. Administration \& Society, 51(8), 1200-1226. https://doi.org/10.1177/0095399716684887

Sousa, J. B., Neto, \& Borges, J. F. (2019). Narrativas de partes Interessadas sob a Perspectiva da Estratégia como Prática Social. Revista de Administração Mackenzie, 20(1), 2-28. https://doi.org/10.1590/1678-6971/ eRAMR190118

North, D. C. (1990). Institutions, institutional change and economic performance. New York: Cambridge University Press.

North, D. C. (1999). Understanding the process of Economic Change. London: lea Occasional Paper.

North, D. C., Wallis, J. J., \& Weingast, B. R. (2009). Violence and social orders: A conceptual framework for interpreting recorded human history. New York: Cambridge University Press.

Nunes, E. O., Nogueira, A. M., Costa, C. C., Andrade, H. V., \& Ribeiro, L. M. (2007). Agências reguladoras e reforma do Estado no Brasil: Inovação institucional e continuidade no sistema político-institucional. Rio de Janeiro: Garamond.

Olson, M. (1965). Logic of collective action: Public goods and the theory of groups (Harvard economic studies. v. 124). Cambridge: Harvard University Press. 
Ollaik, L. G., \& Medeiros, J. J. (2011). Instrumentos governamentais: reflexões para uma agenda de pesquisas sobre implementação de políticas públicas no Brasil. Revista de Administração Pública, 45(6), 1943-1967. https://dx.doi.org/10.1590/S0034-76122011000600015

Ostrom, E. (2014). Collective action and the evolution of social norms. Journal of Economic Perspectives, 14(3), 137-158. https://doi.org/10.1257/jep.14.3.137

O'Toole, L. J. (2015). Networks and networking: The public administrative agendas. Public Administration Review, 75(3), 361-371. https://doi.org/10.1111/puar.12281

Pagnussatt, D., Petrini, M., Silveira, L. M., \& Santos, A. C. M. Z. (2018). Quem são, o que fazem e como interagem: compreendendo os stakeholders em Pequenas Centrais Hidrelétricas. Gestão \& Produção, 25(4), 888-900. https://dx.doi.org/10.1590/0104-530x3676-18

Peci, A., Vieira, M. M. F., \& Clegg, S. R. (2006). A construção do "Real" e práticas discursivas: o poder nos processos de institucionaliz(ação). Revista de Administração Contemporânea, 10(3), 51-71. http://dx.doi.org/10.1590/ $\underline{\mathrm{S} 1415-65552006000300004}$

Phillips, R., Freeman, R. E., \& Wicks, A. C. (2003). What stakeholder theory is not. Business Ethics Quarterly, 13(4), 479-502. https://doi.org/10.5840/beq200313434

Powell, W. (1991). Expanding the scope of institutional analysis. In W. W. Powell \& P. J. DiMaggio (Eds.), The new institutionalism in organizational analysis (pp. 183-203). Chicago: The University of Chicago Press.

Preble, J. F. (2005). Toward a comprehensive model of stakeholder management. Business and Society Review, 110(4), 407-431. http://dx.doi.org/10.1111/j.0045-3609.2005.00023.x

Ribeiro, H. C. M. \& Costa, B. C. (2017). Influência dos Stakeholders na Gestão e no Controle das Organizações Esportivas. Revista Ciências Administrativas, 23(1), 42-69. http://dx.doi.org/10.5020/2318-0722.23.1.42-69

Rossoni, L., \& Machado-da-Silva, C. L. (2013). Legitimidade, governança corporativa e desempenho: Análise das empresas da BM\&F Bovespa. Revista de Administração de Empresas, 53(3), 272-289. http://dx.doi.org/10.1590/ $\underline{\text { S0034-75902013000300005 }}$

Schmidt, V. A. (2008). Discursive institutionalism: The explanatory power of ideas and discourse. Annual Review of Political Science, 11, 303-326. https://doi.org/10.1146/annurev.polisci.11.060606.135342

Scott, W. R. (1995). Instituitions and organizations. Thousand Oakes: Sage.

Streeck, W., \& Thelen, K. A. (Eds.). (2005). Beyond continuity: Institutional change in advanced political economies. Oxford: Oxford University Press.

Vieira, D. M. (2017). Mudança institucional gradual e transformativa: A atuação de stakeholders e coalizões de defesa no caso da UHE Belo Monte. Trabalho apresentado no quadragésimo primeiro Encontro da ANPAD, São Paulo, Brasil. http://www.anpad.org.br/eventos.php?cod_evento=1\&cod_evento_edicao=89\&cod_edicao subsecao $=1453 \&$ cod edicao trabalho $=22997$

Vieira, D. M. (2019). The discourse and coordination among advocacy coalitions: The case of Belo Monte. RAUSP Management Journal, 55(1), 86-99. https://doi.org/10.1108/RAUSP-10-2018-0096

Vieira, D. M., \& Gomes, R. C. (2014). Mudança institucional gradual e transformativa: A influência de coalizões de advocacia e grupos de interesses em políticas públicas. Organizações \& Sociedade, 21(71), 679-694. http:// dx.doi.org/10.1590/S1984-92302014217100008

Voss, G. Z., Voss, G. B., \& Moorman, C. (2005). An empirical examination of the complex relationships between entrepreneurial orientation and stakeholder support. European Journal of Marketing, 39(9/10), 1132-1150. https://doi.org/10.1108/03090560510610761 


\section{Contato:}

Davi de Paula Cabral

E-mail: davicabral2008@gmail.com

Diego Mota Vieira

E-mail: diego1mv@yahoo.com.br 